\title{
A FINANCE MODEL FOR THE REALIZATION OF URBAN TRANSFORMATION PROJECTS: REAL ESTATE VENTURE CAPITAL CROWD FUND
}

\author{
DOI: 10.17261/Pressacademia.2021.1495 \\ PAP- V.14-2021(21)-p.102-105
}

Ilhami Akkum¹, N. Enver Ulger², Mustafa Kurt ${ }^{3}$

${ }^{1}$ Istanbul Okan University, Department of Geomatics Engineering, Tuzla Campus, Istanbul, Turkey. ilhamiakkum@gmail.com, ORCID: 0000-0002-3210-1522

${ }^{2}$ Istanbul Okan University, Department of Geomatics Engineering, Tuzla Campus, Istanbul, Turkey. enver.ulger@okan.edu.tr, ORCID: 0000-0001-7502-7388

${ }^{3}$ Istanbul Okan University, Department of Geomatics Engineering, Tuzla Campus, Istanbul, Turkey. mustafa.kurt@okan.edu.tr, ORCID: 0000-0001-8470-2832

\section{To cite this document}

Akkum, I., Ulger, N.E., Kurt, M., (2021). A finance model for the realization of urban transformation projects: real estate venture capital crowd fund. PressAcademia Procedia (PAP), 14, 102-105.

Permanent link to this document: $\mathrm{http} / / /$ doi.org/10.17261/Pressacademia.2021.1495

Copyright: Published by PressAcademia and limited licensed re-use rights only.

\section{ABSTRACT}

Purpose- Cost considereations arising from risks specific to urban transformation make them difficult to be financed with conventional methods. Real estate investment funds structured in accordance with Turkish Capital Markets Board legislation cannot invest in private sector urban transformation projects. On the other hand, the Blockchain technology enables efficiently distributed trust systems when compared with the central ledger structures. The purpose of this study is to propose a crowdfunding and Blockchain-based, innovative but applicable real estate venture capital investment fund model through smart contracts, as a solution to conventional financing problems arising from the development risks of urban transformation projects.

Methodology- The study employs desktop research, field observations and deductions methodology.

Findings- The analysis reveals that there is a need for decentralized finance need for urban transformation projects.

Conclusion- In this study, which examines the risks in urban transformation projects, risk management, financial support to be used in urban transformation projects and Blockchain-based tools, it was concluded that there are a lot of uncertainties, therefore there are risks. Accordingly, a financing model is proposed for solving valuation and financing problems faced by entrepreneurs in urban transformation projects.

Keywords: Blockchain, Crowdfunding, Real Estate Investment Funds, Smart Contracts, Urban Transformation Financing JEL Codes: D14, 016, 018

\section{KENTSEL DÖNÜŞÜM PROJELERININ GERÇEKLEŞTIRILMESINDE FINANSMAN MODELI: GAYRIMENKUL GIRIŞiM SERMAYESI KITLE YATIRIM FONU}

\footnotetext{
ÖZET

Amaç- Kentsel dönüşüme özgü risklerden kaynaklanan risk maliyetleri konvansiyonel yöntemlerle finansmanı zorlaştırmaktadır. Sermaye Piyasası Kurulu mevzuatına göre yönetilen gayrimenkul yatırım fonları özel sektör kentsel dönüşüm projelerine yatırım yapamamaktadırlar. Diğer yandan Blokzincir teknolojisi tek merkeze dayalı güven sistemlerindeki merkezi güven yapısını dağıtarak, bu sistemlerin daha verimli çalışmasını sağlamaktadır. Bu çalışmanın amacı, kentsel dönüşüm projelerinin geliştirme risklerinden kaynaklanan konvansiyonel finansman sorunlarına, Blokzincir tabanlı, kitlesel fonlama kaynaklı, yenilikçi ancak akıllı sözleşmeler aracılığıyla uygulanabilir bir gayrimenkul girişim sermayesi yatırım fonu modeli önermektir.

Yöntem- Çalışmada literatür araştırma, saha gözlemi ve tümden gelim yöntemleri kullanılmıştır.

Bulgular- Kentsel dönüşüm projelerinin finansmanın merkezsiz finansman kaynaklarının kullanılmasına duyulan gereksinim belirlenmiştir. Sonuç- Kentsel dönüşüm projelerinde risklerin, risk yönetiminin ve kentsel dönüşüm projelerinde kullanılacak finansal desteklerin ve Blokzincir tabanlı araçların incelendiği bu çalışmada çok sayıda belirsizlik, dolayısıyla risk içerdiği sonucu elde edilmiştir. Bu doğrultuda, kentsel dönüşüm projelerinde, girişimcilerin karşı karşıya oldukları değerleme ve finansman sorunlarının çözülebilmesi için bir finansman modeli önerilmektedir.
}

Keywords: Blokzincir, kitle fonlama, gayrimenkul yatırım fonları, akıllı sözleşmeler, kentsel dönüşüm finansmanı JEL Codes: D14, 016, 018 


\section{GíRiş}

Kentlerin yeniden imar ve inşa sürecinde etkin rol oynayan "Kentsel Dönüşüm" projeleri alternatif finansal modellere ihtiyaç duymaktadır. Kentsel dönüşüme özgü risklerden kaynaklanan risk maliyetleri konvansiyonel yöntemlerle finansmanı zorlaştırmaktadır.

Sermaye Piyasası Kurulu mevzuatına göre yönetilen gayrimenkul yatıım fonları özel sektör kentsel dönüşüm projelerine yatırım yapamamaktadırlar. Diğer yandan Blokzincir teknolojisi tek merkeze dayalı güven sistemlerindeki merkezi güven yapısını dağıtarak, bu sistemlerin daha verimli çalışmasını sağlamaktadır.

Yazar kentsel dönüşüm projelerinin geliştirme risklerinden kaynaklanan konvansiyonel finansman sorunlarına, Blokzincir tabanlı, kitlesel fonlama kaynaklı, yenilikçi ancak akıllı sözleşmeler aracılığıyla uygulanabilir bir gayrimenkul girişim sermayesi yatırım fonu modeli önermektedir.

Çevre ve Şehircilik Bakanlığına göre Türkiye'de dönüştürülmesi gereken 6,7 milyon konut olup bu stokun 1,5 milyonunun acil dönüştürülmesi gerekmektedir.

Kentsel dönüşüm projeleri finansman ihtiyacını finansal ekosistemdeki para ve sermaye piyasalarından sağlamaktadır. Bu süreçte çeşitli modeller kullanılmaktadır. Bilinen finansal olanakların yanı sıra, 2010 sonrasında Blokzincir tabanlı araçlar yeni finansman olanakları karşımıza çıkmıştır. İlk olarak Bitcoin tarafından tanıtılan, kayıtların kriptografi kullanılarak bağlandığı sürekli büyüyen dağııı bir veri tabanı olan Blokzincir 1990'lı yıllardan sonra İnternetin yaptığı etkiyi yapacaktır.

Blokzincir dağıtık yapısıyla veri sadece bir merkez tarafından değil, sistem içerisindeki herkes tarafından kayıt altına alınır. Bu yapıda, kötü niyetli birisinin, Blokzincir ağı üzerinde hedef aldığı bir blok içeriğini değiştirebilmesi pratikte olanaksızdır.

Yayılmasını Blokzincire borçlu olduğumuz Akıllı Sözleşmeler içinde mantıksal akışların önceden yazılmış olduğu bir bilgisayar kod bloku olup, ilişkili tarafların kapsam üzerinde anlaşmalarından sonra hazırlanıp, kriptografik olarak imzalanıp, Blokzincir ağına yüklenir. Akıllı sözleşmeler, "güven" amaçlı aracı kurumlara duyulan ihtiyacı azaltmaktadır, daha az insan girdisine/takibine ihtiyaç duymasından dolayı daha düşük maliyetlidir.

Blokzincir ile birlikte girilen "Güven Döneminde" Blokzincir tabanlı akıllı sözleşmeler sayesinde çeşitli paydaşlar stratejisini, iş yapıp biçimini, konusunu onayladıkları bir proje çevresinde bir araya gelebilmekte, yapacakları yatıııın, proje belgelerinde açıklanan ilke, amaç, yöntemler dışında kullanılamayacağından emin olmaktadırlar.

Bildirinin konusunu oluşturan modelin bir SPK fonu olması öngörülmektedir. Yatıııcılardan temin edilecek fonların girişimciye aktarılması portföydeki gayrimenkulün fiziki tamamlanmasıyla mümasil olacak, projenin usulünce yönetilmesi yatırım komitesince risk yönetimi esaslarıla sağlanacaktır.

Önerilen Gayrimenkul Girişim Sermayesi Kitle Yatırım Fonu Modeli ile ilgili tüm yapı Blokzincir üzerinde Akıllı Sözleşmelerle tasarlanacak, kurgulanacak, yapılacak, sürdürülecek, denetlenecektir.

\section{LITERATÜR}

Gayrimenkul yatıım fonları, "nitelikli yatııımcılardan katılma payları karşılı̆ında toplanan paralarla, pay sahipleri hesabına inançlı mülkiyet esaslarına göre Sermaye Piyasası Kurulu (Kurul) tarafından belirlenmiş varlık ve işlemlerden oluşan portföyü işletmek amacıyla portföy yönetim şirketleri ve gayrimenkul portföy yönetim şirketleri tarafından süreli veya süresiz olarak kurulan ve tüzel kişiliği bulunmayan" malvarlıklarıdır.

Girişim sermayesi yatırım fonları, "nitelikli yatıımcılardan katılma payları karşılığında toplanan paralarla, pay sahipleri hesabına inançlı mülkiyet esaslarına göre Sermaye Piyasası Kurulu (Kurul) tarafından belirlenmiş varlık ve işlemlerden oluşan portföyü işletmek amacıyla portföy yönetim şirketleri ve girişim sermayesi portföy yönetim şirketleri tarafından süreli olarak kurulan ve tüzel kişiliği bulunmayan" malvarlıklarıdır.

Kitle fonlaması, "bir projenin veya girişim şirketinin ihtiyaç duyduğu fonu sağlamak amacıyla Kurul tarafından belirlenen esaslar dâhilinde Kanunun yatırımcı tazminine ilişkin hükümlerine tabi olmaksızın kitle fonlama platformları aracılı̆ııla halktan para" toplanmasıdır.

"Blokzincir" teknolojisi, günümüzün önemli problemlerinden olan, tek merkeze dayalı güven sistemlerindeki merkezi güven yapısını dağıtarak, bu sistemlerin daha verimli çalışmasını sağlamaktadır. Blokzincir, veri transferi sağlayan mevcut Internet ortamında, değerli varlıkların transferine de olanak sağlayarak tüm hayatımızı yeniden şekillendirecek yepyeni bir teknolojiyi adlandıran merkezi olmayan bir şifreleme kayıt defteridir."

Akıllı bir sözleşme, bir sözleşmenin koşullarını yerine getiren bilgisayarlaştırılmış bir işlem protokolüdür. Akıllı sözleşme tasarımının temel hedefi ortak sözleşme koşullarını (ödeme koşulları, gizlilik, yaptırımlar gibi) karşılarken, istisnalarla (arızi, kasti...) güvenilir araçlara olan gereksinimi en aza indirmektir. Il gili ekonomik hedeflerse dolandırıııık kökenli kayıpları, tahkim-icra masraflarını, diğer işlem maliyetlerini de düşürmeyi içerir.

Kentsel dönüşüm projelerinin finansmanının sağlanmasında,dönüşüm projesine göre kamu özel ortaklıkları, kamu kurumlarının kendi aralarında oluşturdukları ortaklıklar, özel sektör paydaşlarının kendi içinde oluşturdukları ortaklıklar ya da tekil girişimler oluşabilmektedir. Ancak hangi modelle yapılırsa yapılsın tüm projeler finansman ihtiyacını finansal ekosistemdeki para ve sermaye piyasalarından sağlamaktadır. Bu süreçte "arsa satışı karşıı̆ığı gelir paylaşımı", "kamudan kaynak aktarımı", "kat karşııı̆ı", "banka kredileri", "öz kaynak 
kullanımı", "imar hakkı artışı", "proje kapsamında finansman amaçlı konut/işyeri üretimi” ve "hak sahiplerinin borçlandırılması, daha küçük daire verilmesi" modelleri kullanılmaktadır (Hepşen, 2020).

Kentsel dönüşümde devletçe sağlanan finansal destekler Kira Yardımı ile Kredi ve Faiz Desteğidir. Yararlanılabilecek finansman kaynakları, Konvansiyonel Kaynaklar (Banka Kredileri, Proje Finansmanı, Kentsel Dönüşüm Kredisi) Faizsiz Finansman Ürünleri \{Murabaha (Finansal AlımSatım), Mudarebe (Emek-Sermaye Ortaklığı), Muşareke (Kar/Zarar Ortaklığı), Sukuk (Kira Sertifikası)\} olarak özetlenebilir.

Kentsel dönüşüm projelerinin gerçekleştirilmesinde olası sermaye piyasası olanaklarıysa Bilinen Yatırım Araçları (Gayrimenkul Yatırım Ortaklıkları, Gayrimenkul Yatıım Fonları, Gayrimenkul Sertifikaları) ile Güncel Yatırım Araçları (Girişim Sermayesi, Kitle Fonlama) olarak gruplandırılabilir.

Yeni finansman olanaklarıysa Blokzincir Tabanlı Araçlar olarak adalndırılabilir. Blokzincir teknolojisinin sunduğu Akıllı Sözleşmeler önceden belirlenmiş koşullar karşılandığında çalışan bir Blokzincirde depolanan programlardır. Tipik olarak bir anlaşmanın yürütülmesini otomatikleştirmek için kullanılır; böylece tüm katılımcılar herhangi bir aracının katılımı veya zaman kaybı olmaksızın sonuçtan anında emin olabilirler. Akıllı sözleşmeler, koşullar karşılandığında bir sonraki eylemi tetikleyerek bir iş akışını otomatikleştirebilirler. Blokzincir ekosisteminde "Token" veya belirteç, reel dünyadaki jetonlar gibi veri ve araçlardır. Farklı amaçlarla kullanılmak üzere beş farklı Belirteç tipi bulunur: Kullanım Belirteci (Usage Token), Hak Belirteci (Equity Token), Çalışma Belirteci (Work Token), Topluluk Belirteci (CommunityToken), Varlık Belirteci (Asset Token). Varlık Belirteçleri, şirket hisseleri, gayrimenkul, elmas veya emtia gibi gerçek varlıklara bağlanmış Blokzincir tabanlı değer birimleridir; kullanıcıların sayısal biçimde somut bir varlık üzerinde sahiplik haklarına sahip olmalarını sağlarlar.

\section{VERI VE YÖNTEM}

$\mathrm{Bu}$ çalışmanın motivasyonu kentsel dönüşüm projelerinin geliştirme risklerinden kaynaklanan konvansiyonel finansman sorunlarına, Blokzincir tabanlı, kitlesel fonlama kaynaklı, yenilikçi, ancak akıllı sözleşmeler aracılığıyla, uygulanabilir bir gayrimenkul girişim sermayesi yatırım fonu modeli önerisinde bulunmaktadır.

\section{BULGULAR}

2014 yılında gerçekleştirilen Kentsel Dönüşüm Çalıştayı kapsamında “Kentsel dönüşüm süreci merkeze yakın alanlarda gerçekleştiğinde ister istemez bölgenin değerinin arttığı ve satış değeri ile birlikte dönüşümlerin kendi kendini finanse edebileceği düşünülmektedir." ifadesiyle model önerileri sunulmuştur. Bu çalışmanın sonucunda Sermaye Piyasası Kurulu tarafından bir tebliğ yayımlanması önerilmektedir.

Böylelikle, çok sayıda belirsizlik, dolayısıyla risk içeren kentsel dönüşüm projelerinde, girişimcilerin karşı karşıya oldukları değerleme ve finansman sorunlarının çözümünde kullanılabilecek yalın, saydam ve izlenebilir yararlı bir model için ilk adım atılmış olacaktır.

\section{SONUÇ}

Önerilen gayrimenkul girişim sermayesi kitle yatırım modelinin T.C. Sermaye Piyasası Kanunu ile uyum içinde tasarlanıp, Sermaye Piyasası Kurulu tarafından düzenlenmesi öngörülmektedir.

Fonla ilgili tüm yapının Blokzincir üzerinde kurulması önerilmektedir:

a. Bu amaçla geliştirilen başkaca kamu projeleri (Örneğin Borsa İstanbul Biga Projesi) kıyasen uygulanacak,

b. Fon yapılanması tasarlanacak, oluşturulacak, yapılandırılacak, işletilecek, denetlenecektir.

c. Fonla ilişkili tüm sözleşmeler Akıllı Sözleşme olarak tasarlanacak, kurgulanacak, yapılacak, sürdürülecek, denetlenecektir.

d. Fon içi tüm nakit, varlık, yükümlülük el değiştirmeleri Blokzincir ortamında Akıllı Sözleşmelerle gerçekleştirilecektir.

e. Kanunen ilgili Kamu Kurumunda (örneğin tapu devri) yapılması zorunlu işlemler dışında tüm sözleşmeler (örneğin tasarım, yapım, hizmet, tedarik v.b. tüm İşveren - Ana Yüklenici, Yüklenici - Alt Yüklenici, İşveren - Tedarikçi Sözleşmeleri) Blokzincir ortamında Akıllı Sözleşmeler biçiminde oluşturulacaktır.

f. Gerek Fon Yatırım Komitesi, gerek Fon Denetçileri, gerekse de SPK tarafından tüm Blokzincir'in gerçek zamanlı olarak izlenebilmesi, denetlenebilmesi, sorgulanabilmesi elektronik olarak sağlanacaktır.

Paydaş ilişkileri çerçevesinde; akılı sözleşmelerin hangi ortamda, hangi teknolojiler kullanılarak, hangi paydaşlar tarafından kurgulanacağı başlıca düzenleyici kurumlar olan, TC Hazine ve Sermaye Bakanlığı, TC Maliye Bakanlığı, TC Çevre ve Şehircilik Bakanlığı, Sermaye Piyasası Kurulu tarafından mevzuata dönüştürülecektir. Bu çerçevede önerilen Gayrimenkul Girişim Sermayesi Kitle Yatırım Fonu Tebliği'nin gayrimenkulün menkulleştirilmesi, sermayenin sayısallaştırılmasında gerekli altyapıyı sağlayacağı düşünülmektedir.

\section{KAYNAKÇA}

Alkış, A. (2018) İslam Hukukunda Katılım Bankacılığı Fon Toplama ve Kullandırma Yöntemleri. Al-Farabi Uluslararası Sosyal Bilimler Dergisi. 2(3). 120-133.

Avcu, E. C. (2015). Katılım Bankacılığı ve Sukuk Modelleri. (Yüksek Lisans Tezi). Süleyman Demirel Üniversitesi Sosyal Bilimler Enstitüsü. Isparta. 31-32. 
Bayındır, S. (2005). Bir Finansman Yöntemi Olarak Kullanılan Sermaye Ortaklığının İslâm Hukuku Açısından Değerlendirilmesi. Usul İslam Araştırmaları. 3(3). 140-141.

Candaş, E. (2012). Taşınmaz Değerlemesi İçin Mevzuat Altyapısının Modellenmesi. (Yüksek Lisans Tezi). İstanbul Teknik Üniversitesi Fen Bilimleri Enstitüsü. İstanbul. 8.

Çelik, İ. (2017). Meşru’Bir Yatırım Aracı Olarak Mudarebe ve Günümüzde Kullanımı. Farabi Uluslararasi Sosyal Bilimler Dergisi. 1(3). $381-395$.

Çubukçu, C. (2017). Kitlesel Fonlama: Türkiye'deki Kitlesel Fonlama Platformları Üzerinden Bir Değerlendirme. Girişimcilik ve İnnovasyon Dergisi. 6(2017). 155-172.

Ercan, S. (2017). Türkiye'de Kitlesel Fonlama: Destekçilerin Motivasyonu,Ekonomi, İşletme ve Yönetim Dergisi. 1(1). 1-9.

Ertürk, H., Sayılgan, G. (2014). Girişim Sermayesi Fonları ve Bu Fonların Geliştirilmesinde Kamunun Rolü. İstanbul Üniversitesi İşletme

Fakültesi Dergisi. 43(2014). 293-318.

Gayrimenkul ve Gayrimenkul Yatırım Ortaklığı Derneği. (2021). Türkiye Gayrimenkul Sektörü 2021 2. Çeyrek Raporu. 25(2021). 7.

Gedik, T., Akyüz, K. C., Akyüz, İ. (2005). Yatırım Projelerinin Hazırlanması ve Değerlendirilmesi (İç Karlılık Oranı ve Net Bugünkü Değer

Yöntemlerinin İncelenmesi). 7(7). 51-61.

Hepşen, A. (2020). Kentsel dönüşüm Ekonomik ve Finansman Boyutu. https://silo.tips/download/kentsel-dnmn-ekonomk-ve-fnansmanboyutu-dodr-al-hepen\#modals. Silo.tips. Web. [Erişim tarihi: 28 Aralık 2020].

İpekten, O. B. (2010). Rísk Sermayesi Finansman Modeli. Atatürk Üniversitesi Sosyal Bilimler Enstitüsü Dergisi. 7(1). 385-408.

Karahan, H., Ersoy, H. (2016). Faizsiz Finansın Temel Prensipleri ile Türkiye'de Reel Kesimde Kullanılması. Maliye Finans Yazıları. 2016(105). 93-114.

Köroğlu, A. (2016). Gayrimenkul sertifikası modeli ve Türkiye’de uygulanabilirliği. Gazi İktisat ve İşletme Dergísi. 2(1). 25-42.

Mutlu, S. (2007). Türkiye'de Yaşanan Gecekondulaşma Süreci ve Çözüm Arayışları: Ankara Örneği. (Yüksek Lisans Tezi). Ankara Üniversitesi Sosyal Bilimler Enstitüsü. 96.

Özbay, F. (2014). Katılım Bankacılığı ve Türkiye' deki Uygulamaları. (Yüksek Lisans Tezi). Gediz Üniversitesi Sosyal Bilimler Enstitüsü. 45.

Polat, A., Yeşilyaprak, M. (2018). Kefalet Sigortası'nın Türk Finansal Kesiminde Uygulanması ve Muhtemel Etkileri. Maliye Finans

Yazıları. 110. 135-160.

Sakarya, Ş., Bezirgan, E. (2018). Kitlesel Fonlama Platformları: Türkiye ve Yurtdışı Karşılaştırması, Düzce Üniversitesi Sosyal Bilimler Enstitüsü Dergisi. 2. 18-33.

Südaş, İ. (2004). 17 AĞUSTOS 1999 MARMARA DEPREMININ NÜFUS VE YERLEŞME ÜZERINDEKI ETKILERI: GÖLCÜK (KOCAELI) ÖRNEĞi. Ege Coğrafya Dergisi, 13(2004), 73-91.

Ülger, N.E. (2010). Türkiye'de Arsa Düzenlemeleri ve Kentsel Dönüşüm. Nobel Yayın. 185, 293. 